Check for updates

Cite this: RSC Adv., 2018, 8, 11087

Received 21st January 2018

Accepted 12th March 2018

DOI: $10.1039 / c 8 r a 00617 b$

rsc.li/rsc-advances

\section{Effect of chemical pretreatments on magnetic susceptibility of loess from Central Asia and the Chinese Loess Plateau}

\author{
Yougui Song, (DD *ab Yue Li, (D) ac Qiansuo Wang, ${ }^{d}$ Hongmei Dong, ${ }^{e}$ Zhiping Zhang ${ }^{f}$ \\ and Rustam Orozbaev (iD gh
}

Magnetic susceptibility (MS) as a paleoclimatic proxy plays an important role in paleoenvironmental reconstruction and past global climatic change. In order to discriminate the effect of composition on the MS of Quaternary eolian loess in inland arid Central Asia (CA), a series of comparative chemical experiments were designed to investigate the effects of different components on MS of loess from the Ili Basin CA and Chinese Loess Plateau (CLP). The results indicate that hydrochloric acid $(\mathrm{HCl})$ can not only remove carbonate minerals, but also react with ferrous ions minerals by dissolving fine superparamagnetic particles (SPS), which reduces MS, especially in the CLP samples. Compared to the original samples, MS ( $\left.\chi_{\mathrm{If}}\right)$ of acetic acid (AA) pretreated samples from CA and CLP increased by $20.3 \%$ and $4.8 \%$, respectively, and their frequency-dependent $M S\left(\chi_{\mathrm{fd}}\right)$ increased by $53.4 \%$ and $13.0 \%$, respectively, which indicates that the effect of carbonates on MS is greater for CA samples than for CLP samples. The variation in MS was below $5 \%$ in samples pretreated with perhydrol $\left(\mathrm{H}_{2} \mathrm{O}_{2}\right)$ or distilled water, indicating that organic material and soluble components have very small influences on the MS. Temperaturedependence MS curves indicate that the transformation of magnetic minerals during the cooling of loess from the CLP mainly affected fine particles in the SPs, and that the contents of lepidocrocite and maghemite or goethite in the CA loess are lower than those in the CLP. The loess MS enhancement mechanism in Central Asia differs from that in the CLP.

\section{Introduction}

In paleoclimatological studies of loess from the Chinese Loess Plateau (CLP) ${ }^{\mathbf{1 - 4}}$ and European loess, ${ }^{5-8}$ magnetic susceptibility (MS) is regarded as an important climatological indicator and plays an important role in the study of past global change. ${ }^{2,9-12}$ The primary mechanisms that enhance the MS of Quaternary loess include pedogenesis, ${ }^{\mathbf{1 3 - 1 5}}$ the dilution of falling cosmic

${ }^{a}$ State Key Laboratory of Loess and Quaternary Geology, Institute of Earth Environment, Chinese Academy of Sciences, Xi'an, 710061, China. E-mail: syg@ ieecas.cn

${ }^{b}$ Department of Geosciences, Baylor University, Waco, TX 76798, USA. E-mail: Yougui_song@baylor.edu

${ }^{c}$ College of Earth Science, University of Chinese Academy of Sciences, Beijing, 100049, China

${ }^{d}$ College of Resources and Environment, Linyi University, Linyi 276005, Shandong, China

${ }^{e}$ School of Management, Xi'an University of Science and Technology, Xi'an 710054, China

${ }^{f}$ Environmental Monitoring Station of Ili Kazakh Autonomous Prefecture, Yining 835000, China

${ }^{g}$ Institute of Geology, National Academy of Sciences of Kyrgyz Republic, Bishkek 720040, Kyrgyzstan

${ }^{h}$ Research Center for Ecology and Environmental of Central Asia (Bishkek), Bishkek, 720040, Kyrgyzstan dust, ${ }^{16}$ sediment compaction and carbonate leaching, ${ }^{17}$ and the decomposition of plant residues. ${ }^{18}$ The pedogenesis mechanism, which is widely accepted, suggests that the higher MS of paleosols relative to loess in the CLP is caused by the superparamagnetic particles (SPs) formed by pedogenesis. ${ }^{\mathbf{1 3 - 1 5}}$ However, the mechanism causing MS enhancement in the loess of non-monsoon areas remains unclear (such as in the westerly wind zone in arid Central Asia). ${ }^{19-26}$ Lü et al. ${ }^{27}$ applied the citrate-bicarbonate-dithionite (CBD) method to study loess MS enhancement across the CLP and Tianshan in Central Asia. They found that the CBD method cannot provide pedogenetic information in the arid area of the Tianshan, and cannot distinguish between primary and secondary magnetic minerals.

The loess from arid CA often contains soluble salts, carbonates and organic materials, yet not studies have reported the influence of these compounds on MS. Carbonate minerals are anti-magnetic. Heller and $\mathrm{Liu}^{\mathbf{1 7}}$ suggested that carbonates in loess reduce the MS, and that the leaching of carbonates can enhance the MS. Selective acid leaching experiments on loess indicate that hydrochloric acid $(\mathrm{HCl})$ can dissolve carbonate materials and destroy many silicate minerals. ${ }^{28}$ Acetic acid (AA), however, can selectively leach carbonate components in loess and paleosols, but has a very small effect on silicates and iron oxides. $^{29}$ There is a positive correlation between the organic 
mineral content and MS. ${ }^{30,31}$ Organic minerals have a distinct MS, which depends on the degree of carbon polymerization, and they can also vary from paramagnetic to diamagnetic. ${ }^{32}$ In order to determine the effect of composition on the MS of eolian loess in the inland arid CA, the authors conducted a series of comparative experiments to remove organic material/soluble salt using distilled water or perhydrol $\left(\mathrm{H}_{2} \mathrm{O}_{2}\right)$, and furthermore remove carbonates using $\mathrm{HCl}$ or AA. The results were compared with those using loess samples from the CLP.

\section{Setting and sampling}

The trumpet-shaped Ili Basin, surrounded by branches of the Tianshan Mountains in Central Asia, is a favourable geomorphological setting for dust deposition. Loess is widely distributed across the Ili Basin, mainly on different terraces of the Ili, Kunes, Tekes and Kashi rivers; the piedmont; and desert margins. ${ }^{33}$ The loess in the Ili Basin has typical characteristics of eolian deposits. ${ }^{33}$ In total, 12 loess and paleosol samples were collected from the Zhaosu Poma (ZSP) section $\left(80.25^{\circ} \mathrm{E}\right.$, $\left.42.69^{\circ} \mathrm{N}\right)^{34-37}$ and Talede (TLD) section $\left(83.01^{\circ} \mathrm{E}, 43.42^{\circ} \mathrm{N}\right)^{19,38,39}$ at the southern margin of the Ili Basin (Fig. 1). Both loess sections are situated on river terraces, close to the southern Tianshan Mountains. The ZSP loess section is $6.9 \mathrm{~m}$ thick and has mainly been deposited since the last glacial period. ${ }^{20}$ The TLD loess section is approximately $30 \mathrm{~m}^{\text {thick }} \mathrm{kg}^{\mathbf{3 9} 40}$ (Fig. 1b), and we collected loess samples from the uppermost $6 \mathrm{~m}$. Because the MS enhancement mechanism of the CLP loess has been well documented during the past several decades, ${ }^{3,11,15,17,41-43}$ here we select 6 samples from the Weinan (WN) loess section $\left(109.6^{\circ} \mathrm{E}\right.$, $34.5^{\circ} \mathrm{N}$ ) deposited since the last interglacial period ${ }^{44}$ on the south-eastern margin of the CLP (Fig. 1a) for comparison. A comprehensive comparative study is helpful for understanding the differences and similarities of MS enhancement between these sites.

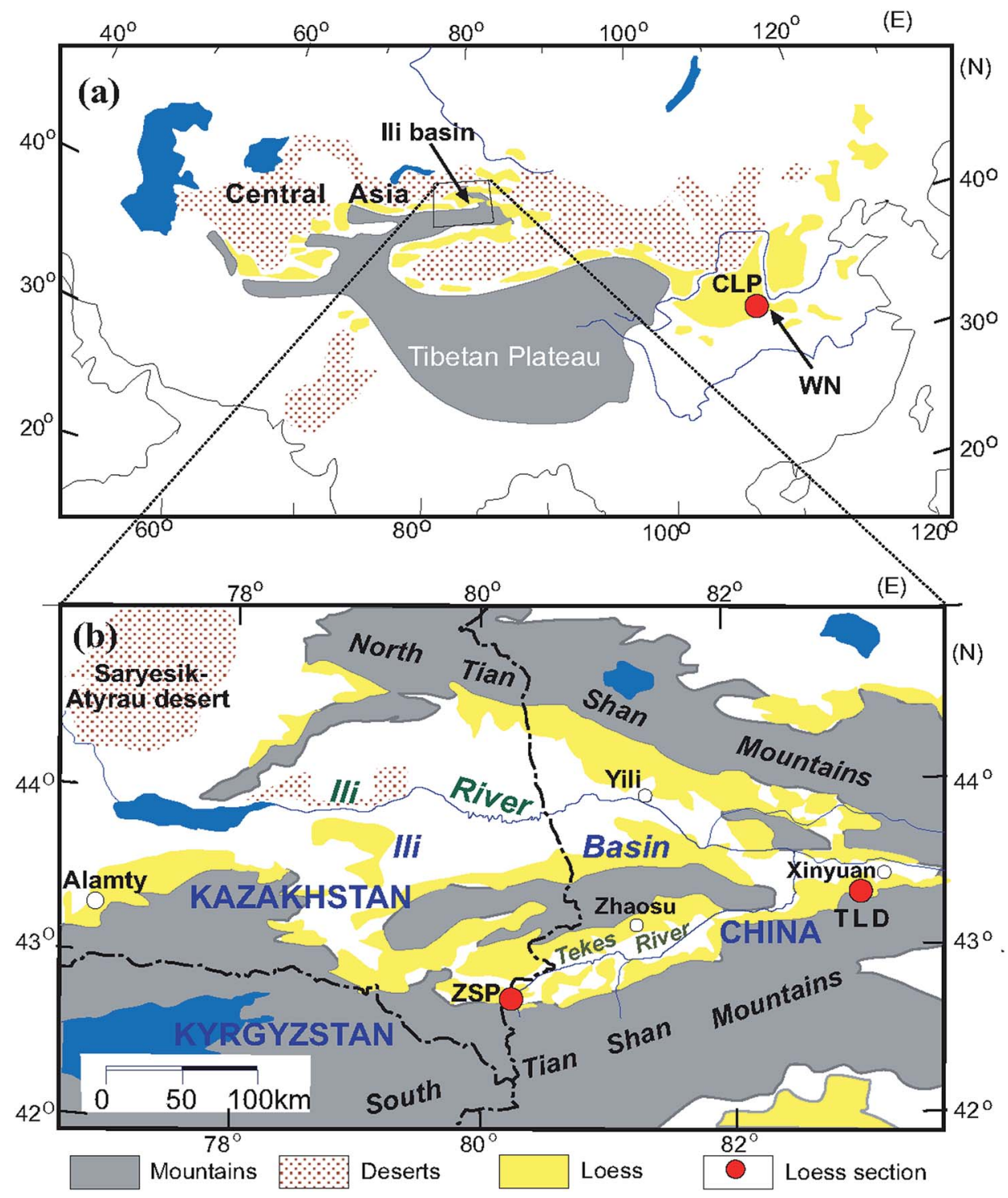

Fig. 1 Loess sections locations in the Chinese Loess Plateau (a) and the Ili Basin of Central Asia (b) (modified from Song et al., 2014). 


\section{Methods}

\subsection{Pretreatment}

The loess samples were dried in an oven at a temperature of $50{ }^{\circ} \mathrm{C}$, and were then thoroughly mixed by coarsely grinding in an agate mortar. For both the CA loess and the CLP loess, four $15 \mathrm{~g}$ subsamples of each sample were retrieved and marked as A, B, C and D. The subsamples were placed in a $450 \mathrm{ml}$ centrifuge cup after measuring the MS. Next, $50 \mathrm{ml}$ of distilled water was added to the A samples to remove soluble salt; $50 \mathrm{ml}$ of $\mathrm{H}_{2} \mathrm{O}_{2}$ solution $(10 \%)$ was added to the $\mathrm{B}$ subsamples to remove organic materials; $50 \mathrm{ml}$ of AA $(10 \%)$ was added to the $\mathrm{C}$ subsamples to remove calcium carbonate; $50 \mathrm{ml}$ of $\mathrm{HCl}(10 \%)$ was added to the D subsamples to remove carbonate minerals and possibly other ferrous minerals. All subsamples were stirred multiple times and left to stand for more than $48 \mathrm{~h}$ to allow the subsamples to effectively disperse and fully react. Distilled water was added to the centrifuge cup, the subsamples were centrifuged at $5000 \mathrm{rpm}$ for $15 \mathrm{~min}$, and the clear water at the top of the cup was decanted. This process was repeated until the $\mathrm{pH}$ value of the water became neutral. Residues were collected and dried at a constant temperature of $50{ }^{\circ} \mathrm{C}$. The subsamples were weighed, and the MS was measured. To test the degree of carbonate removal, we used an X-ray diffractometer to identify variations in mineralogy (Fig. 2). The air-dried loess sediments were ground by hand using an agate mortar and pestle to about 300 mesh size $(<40 \mu \mathrm{m})$, then the powder samples were scanned from 3 to $70^{\circ}(2 \theta)$ at generator settings of $40 \mathrm{~mA}$ and $40 \mathrm{kV}$ using a Philips X'pert Pro (PW3071) X-ray diffractometer with $1.540598 \AA \mathrm{CuK} \alpha$ radiation. The diffraction spectrum did not show the characteristic peaks of carbonate minerals such as calcite, dolomite, which indicates that they were removed completely (Fig. 2). After the subsamples were fully reacted with an $\mathrm{H}_{2} \mathrm{O}_{2}$ solution and dried at $50{ }^{\circ} \mathrm{C}$, they were baked at $550{ }^{\circ} \mathrm{C}$. The weights did not change significantly, which indicates that the organic minerals were thoroughly removed by this method.

\subsection{Magnetic measurements}

Magnetic susceptibility measurements were made on $10 \mathrm{~g}$ dry powder samples at low $(\mathrm{LF}=0.47 \mathrm{kHz})$ and high $(\mathrm{HF}=4.7 \mathrm{kHz})$ frequencies in a Bartington Instruments dual frequency MS2B sensor and expressed as mass-specific magnetic susceptibility $\left(\chi_{\mathrm{lf}}, \chi_{\mathrm{hf}}\right)$, mass-specific frequency-dependent susceptibility $\left(\chi_{\mathrm{fd}}\right)$ and percentage frequency-dependent susceptibility $\left(\chi_{\mathrm{fd}} \%\right) \cdot \chi_{\mathrm{fd}}$ is defined as $\chi_{\mathrm{lf}}-\chi_{\mathrm{hf}}$, and $\chi_{\mathrm{fd}} \%$ is defined as $\left(\chi_{\mathrm{lf}}-\chi_{\mathrm{hf}}\right) / \chi_{\mathrm{lf}} \times$ $100 \%$. The MS variation curve $(\chi-T)$ of MS with temperature was measured using an AGICO Inc KLY-3s Kapabridge and CS-3
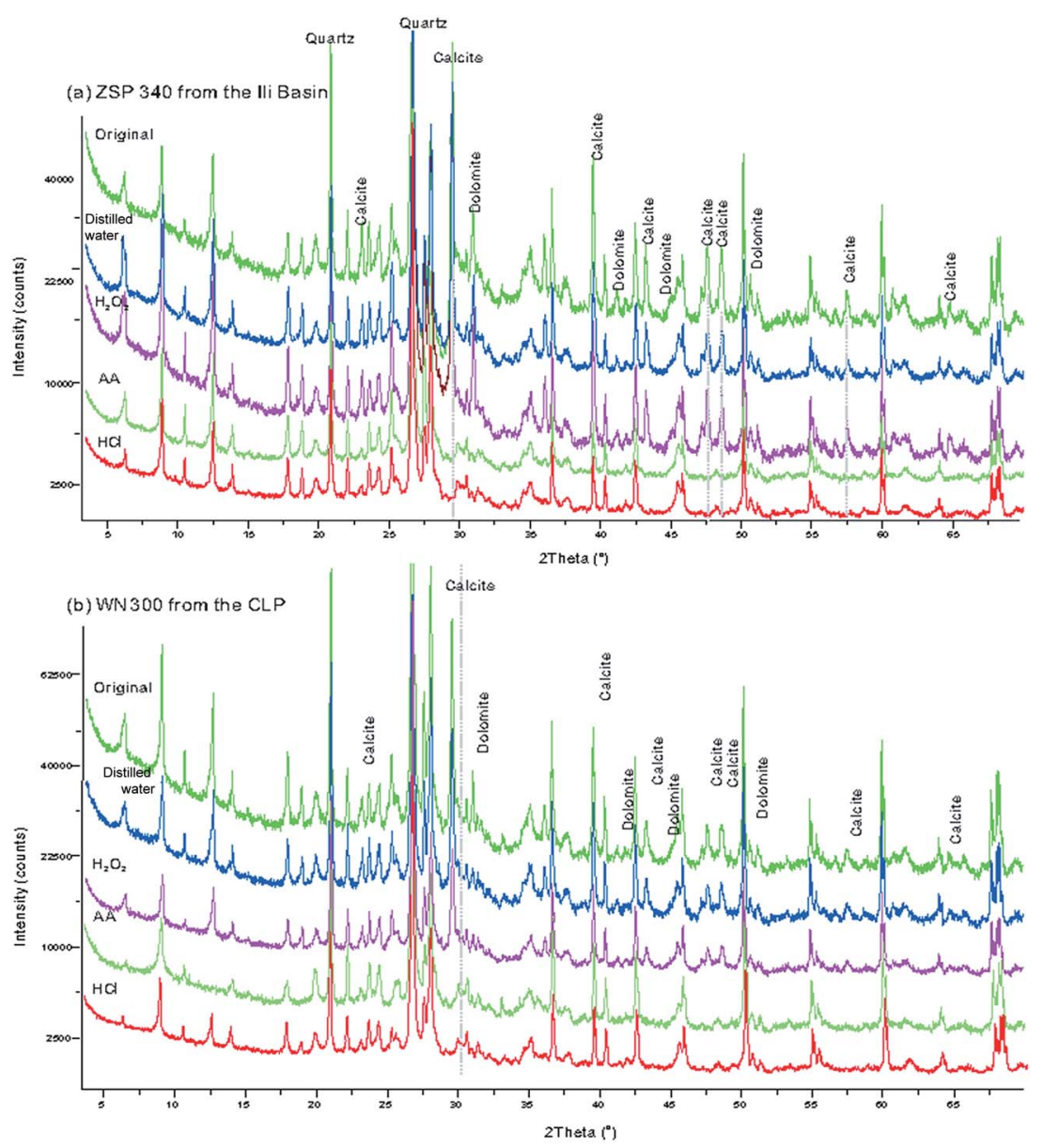

Fig. 2 X-ray diffraction patterns with different pretreated methods of selected samples from the lli Basin (a) and the CLP (b). 


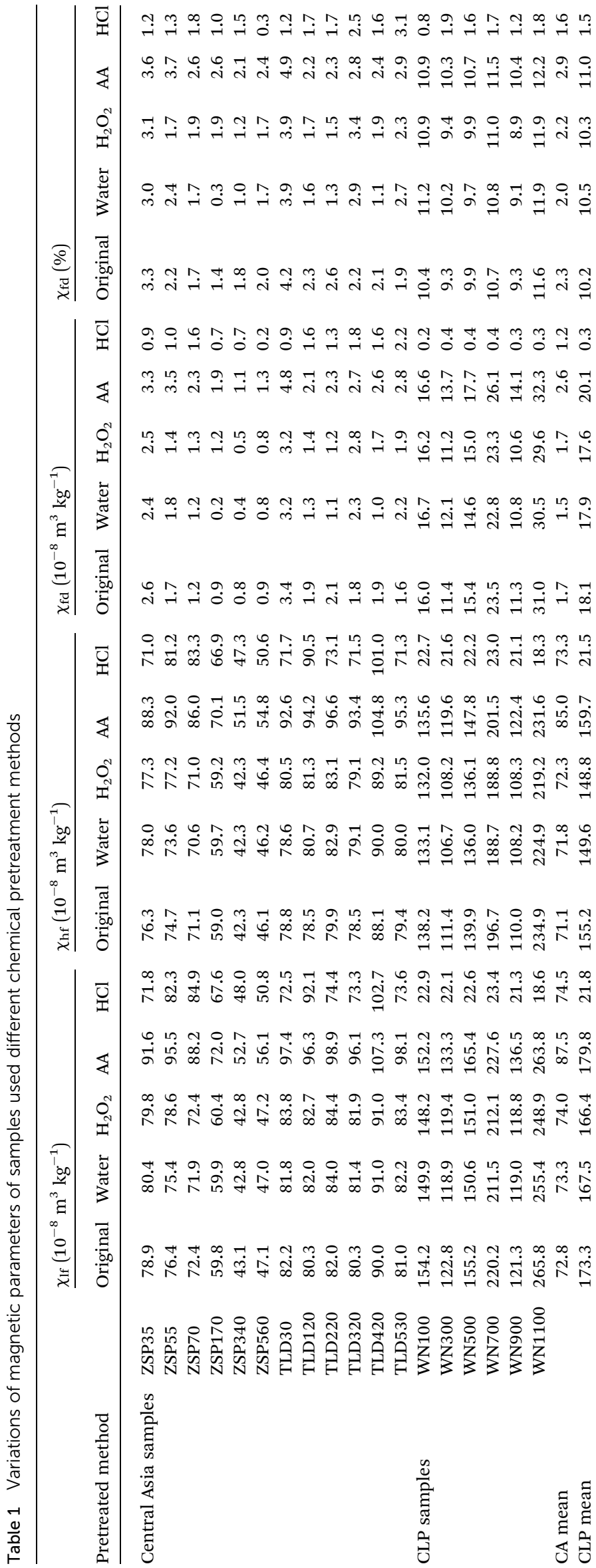


temperature control system with approximately $0.2 \mathrm{~g}$ of powder samples. To prevent the samples from being oxidized during heating, the entire experiment was performed in an argon environment. All measurements were completed in the State Key Laboratory of Loess and Quaternary Geology, Chinese Academy of Sciences (CAS).

\section{Results}

Table 1 shows the values of magnetic parameters $\left(\chi_{\mathrm{lf}}, \chi_{\mathrm{hf}}, \chi_{\mathrm{fd}}\right.$, $\left.\chi_{\mathrm{fd}} \%\right)$ of all samples before and after pretreatment with different methods. Generally, both mass-specific magnetic susceptibility $\left(\chi_{\mathrm{lf}}, \chi_{\mathrm{hf}}\right)$ and frequency-dependent susceptibility $\left(\chi_{\mathrm{fd}}, \chi_{\mathrm{fd}} \%\right)$ in the original samples from the CA are significantly lower than those of loess samples from the CLP. In particular, the values of frequency-dependent susceptibility are very low $(<5$ $\times 10^{-8} \mathrm{~m}^{3} \mathrm{~kg}^{-1}$ or $<5 \%$ ) (Table 1 ). The absolute differences between CLP samples are larger than those of the CA samples. The maximum $\chi_{\text {lf }}$ difference in value of WN1100 from the CLP reached $247.2 \times 10^{-8} \mathrm{~m}^{3} \mathrm{~kg}^{-1}$. The absolute $\chi_{\text {lf }}$ differences of the CA samples were clearly smaller, with a maximum of $13.0 \times$ $10^{-8} \mathrm{~m}^{3} \mathrm{~kg}^{-1}$. However, most of the percentage increases or decreases in the CA loess were greater than those of the CLP loess, except $\mathrm{HCl}$ (Fig. 3). The most prominent changes in magnetic parameters were that all $\mathrm{HCl}$-pretreated samples from the CLP decreased significantly, with average percentage decreases ranging from $84.9 \%$ to $98.0 \%$ (Fig. 3). In contrast, both $\chi_{\mathrm{lf}}\left(\right.$ or $\left.\chi_{\mathrm{hf}}\right)$ and $\chi_{\mathrm{fd}}\left(\right.$ or $\chi_{\mathrm{fd}} \%$ ) of loess samples from CA showed no statistically significant changes after the samples were pretreated with $\mathrm{HCl}$ (Fig. 3 and Table 1). Magnetic parameters of most samples (except WN100 and WN1100) increased after they were pretreated with AA, and the increments of the CA samples were obviously higher than those of the CLP samples (Fig. 3). The mean values of $\chi_{\mathrm{lf}}$ and $\chi_{\mathrm{hf}}$ in the CA samples increased by $20.3 \%$ and $19.6 \%$, respectively, but their increments in the CLP samples were only $4.8 \%$ and $3.9 \%$, respectively (Table 1). Mean values of $\chi_{\mathrm{lf}}$ and $\chi_{\mathrm{hf}}$ in CA and CLP samples pretreated with distilled water and $\mathrm{H}_{2} \mathrm{O}_{2}$ varied by less than $4 \%$, while $\chi_{\mathrm{fd}}$ variations exceeded $17 \%$ in most CA samples pretreated with distilled water. $\chi_{\mathrm{fd}}$ and $\chi_{\mathrm{fd}} \%$ variations in both CA and CLP samples were less than $5 \%$ when pretreated with $\mathrm{H}_{2} \mathrm{O}_{2}$.

\section{Discussion}

In samples pretreated with $\mathrm{HCl}$, the $\chi_{\mathrm{lf}}$ and $\chi_{\mathrm{fd}}$ of CLP samples decreased from means of $173.4 \times 10^{-8}$ to $21.8 \times 10^{-8} \mathrm{~m}^{3} \mathrm{~kg}^{-1}$ and $18.1 \times 10^{-8}$ to $0.3 \times 10^{-8} \mathrm{~m}^{3} \mathrm{~kg}^{-1}$ (Table 1 ), respectively, indicating a greater than $86 \%$ reduction in $\chi_{\text {lf }}$ and $98 \%$ reduction in $\chi_{\mathrm{fd}}$. Meanwhile, there were no significant changes in CA samples. The $\chi_{\mathrm{fd}}$ is the difference between $\chi_{\mathrm{lf}}$ and $\chi_{\mathrm{hf}}$, and is thus regarded as an indicator to reflect the formation of the fine
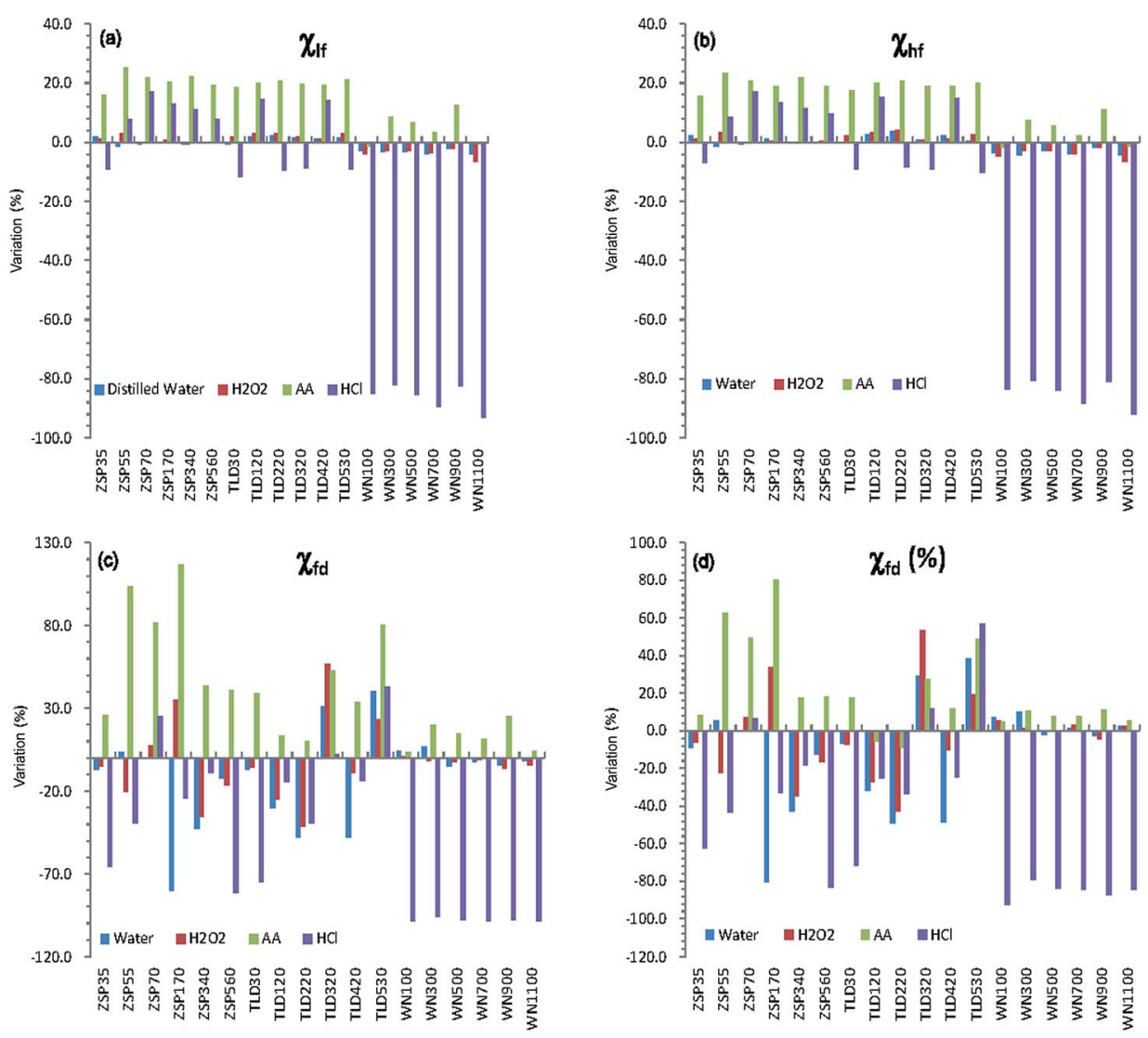

Fig. 3 Column diagrams of magnetic parameters variations relative to the original samples from Central Asia (prefixed by ZSP and TLD) and the Chinese Loess Plateau (prefixed by WN) pretreated with different methods. 
magnetic particles near the threshold $(\sim 20-25 \mathrm{~nm})^{45}$ of the stable domain (SD) and superparamagnetic (SP) of ferromagnetic minerals during the continuous pedogenesis of soils. $\chi_{\mathrm{fd}}$ can be used to measure the absolute concentration of SP and its contribution to MS. ${ }^{\mathbf{1 0 , 4 6 , 4 7}}$ While $\chi_{\mathrm{fd}} \%$ is controlled by both grain size distribution and the concentration of particles near the SP/ SD threshold, ${ }^{47}$ it is sensitive only to a very narrow portion of the grain size distribution near the SP/SD threshold. Therefore, the MS enhancement of the CLP is mainly caused by SPs formed during pedogenesis, ${ }^{11}$ further supporting the pedogenetic model for the CLP. Here, $\chi_{\mathrm{fd}} \%$ values less than $5 \%$ indicate that SPs have a limited contribution to the MS. ${ }^{35,48}$ Specifically, $\chi_{\mathrm{fd}} \%$ values $(<5 \%)$ of the CA loess samples indicate that the enhanced MS of the Ili loess is mainly associated with coarse particles.

In samples pretreated with $\mathrm{AA}$, the $\chi_{\mathrm{fd}}$ of loess samples from CA and the CLP increased by $0.9 \times 10^{-8}$ and $2.1 \times 10^{-8}$ $\mathrm{m}^{3} \mathrm{~kg}^{-1}$, respectively, amplifying initial values by $53.4 \%$ and $13.2 \%$, respectively. Due to the effect of secondary carbonates on the MS of loess, their removal will cause relative enrichment of the magnetic minerals, thus increasing the MS. Compared to the CLP samples, the removal of carbonates increased the $\chi_{\text {lf }}$ of loess samples from CA by an average of $14.7 \times 10^{-8} \mathrm{~m}^{3} \mathrm{~kg}^{-1} \cdot \chi_{\mathrm{lf}}$ increased by an average of $6.6 \times 10^{-8} \mathrm{~m}^{3} \mathrm{~kg}^{-1}$ in loess samples from the CLP, which is much smaller than that for loess samples from CA. Because CA is an arid inland area, a larger amount of secondary carbonate is formed during soil formation, ${ }^{\mathbf{4 9}}$ and there is a greater accumulation of carbonates than on the CLP. Except for the part of the paleosol that experienced eluviation, loess, weakly developed paleosol, and ancient soil are abundant in carbonates. Therefore, the influence of carbonates on MS is more significant in loess samples from CA than in those from the CLP.

The mean $\chi_{\mathrm{fd}}$ of CA samples pretreated with distilled water was reduced by $11.8 \%$, and the $\chi_{\text {lf }}$ of CA samples increased slightly (by $0.6 \%$ ). Meanwhile, both $\chi_{\mathrm{lf}}$ and $\chi_{\mathrm{fd}}$ in the CLP samples showed no obvious changes. The variations in mean values of $\chi_{\mathrm{lf}}, \chi_{\mathrm{hf}}, \chi_{\mathrm{fd}}$ and $\chi_{\mathrm{fd}}$ from both CA and CLP samples pretreated with $\mathrm{H}_{2} \mathrm{O}_{2}$ and distilled water were less than $5 \%$, except in the $\chi_{\mathrm{fd}}$ and $\chi_{\mathrm{fd}} \%$ of CA samples pretreated with distilled water (Fig. 3), which indicates that the soluble mineral content and organic minerals in the loess samples have a very small effect on the MS. This result is also supported by the consistency (almost a complete overlap) between the $\chi_{\text {lf }}$ curves for the original samples and those pretreated with distilled water or $\mathrm{H}_{2} \mathrm{O}_{2}$. The change in $\chi_{\mathrm{fd}}$ and $\chi_{\mathrm{fd}} \%$ was relatively large for CA samples, which is most likely due to the relatively small SPs in CA loess and paleosol (generally $0.8-2.5 \times 10^{-8} \mathrm{~m}^{3} \mathrm{~kg}^{-1}$ ) samples. The background values measured in air after finishing measurement of samples were generally $(-0.3$ to 0.3$) \times 10^{-8}$ $\mathrm{m}^{3} \mathrm{~kg}^{-1}$, which caused a relatively large variation. Therefore, the change in $\chi_{\mathrm{fd}}$ does not properly reflect the change in the SPs content.

A curve showing the variation in MS with temperature (TDS curve) (Fig. 4) demonstrates that the magnetic minerals transform during the thermal demagnetization process. ${ }^{50-54}$ The cooling curve is superposed on the heating curve, which
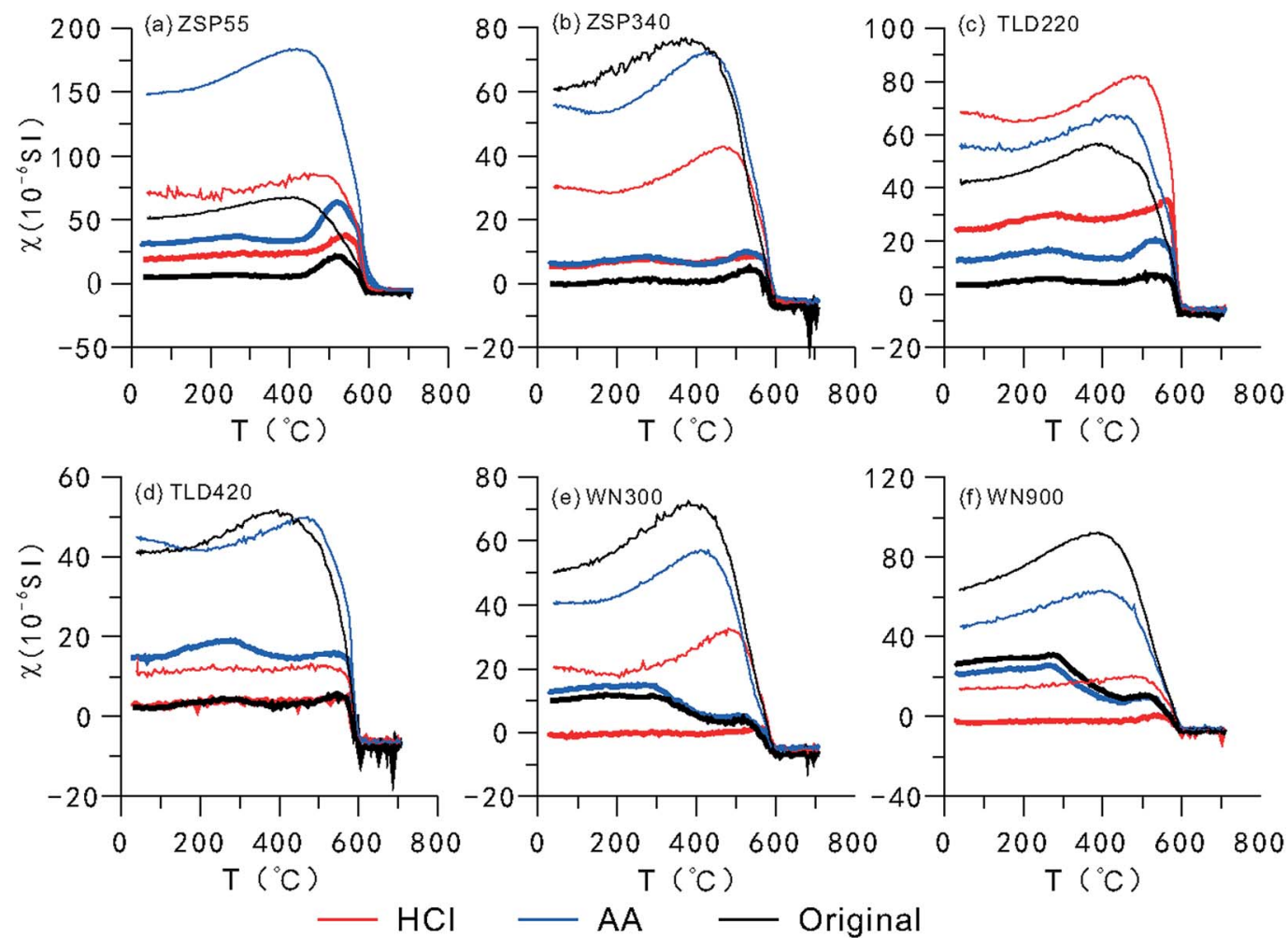

AA

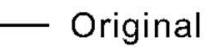

Fig. 4 The MS-temperature curves for loess samples pretreated with different methods from Central Asia and the Chinese Loess Plateau. Bold and thin lines represent heating and cooling, respectively, and red and blue lines represent samples pretreated with $\mathrm{HCl}$ and $\mathrm{AA}$, respectively. 
indicates that new magnetic minerals are formed during the cooling process. ${ }^{\mathbf{2 0 , 4 6 , 5 0 , 5 2 , 5 4}}$ As shown in Fig. 4, the MS of loess from the two areas abruptly decreases or increases during heating or cooling to near $580{ }^{\circ} \mathrm{C}$, which indicates that magnetite is the main contributor to MS and is the dominant component of the newly-formed magnetic minerals. The number of magnetic minerals formed during cooling can be determined based on how much higher the cooling curve is relative to the heating curve. According to the results of CLP samples (Fig. 4e and f), there were few new magnetic minerals formed in the HCl-pretreated samples during the cooling process, and there was no significant difference between the original samples and the AA-pretreated samples, which indicates that the fine particle fraction in SPs most likely had a relatively significant contribution to the transformation of magnetic minerals. Because the SP contents were relatively lower in the Ili loess, CA, and although their size was relatively large, the difference is not obvious except for in samples B and D. Meanwhile, during the heating process, the original samples and the AA-pretreated samples from the CLP exhibited a peak near $260{ }^{\circ} \mathrm{C}$ and $520{ }^{\circ} \mathrm{C}$, respectively, most likely caused by the transformation of lepidocrocite to maghemite ${ }^{55}$ and the formation of magnetite from the pyrolysis of iron silicate minerals or clay minerals. ${ }^{35}$ Between $300{ }^{\circ} \mathrm{C}$ and $440{ }^{\circ} \mathrm{C}$, the MS decreases as the temperature increases, which is generally attributed to the transformation of maghemite or goethite into hematite. ${ }^{53-55}$ In CA samples, these characteristics were indistinct in all samples except for D, which was pretreated with AA. This indicates that there is less lepidocrocite and maghemite or goethite in the Ili Basin loess than in the CLP loess. During the heating of the HCl-pretreated samples, the CA and CLP samples did not exhibit peaks near $260^{\circ} \mathrm{C}$, and decreased from $300^{\circ} \mathrm{C}$ to $440^{\circ} \mathrm{C}$. Therefore, the numbers of lepidocrocite and maghemite or goethite particles in the SPs are most likely very limited.

\section{Conclusions}

A comparison of $\chi_{\mathrm{lf}}$ and $\chi_{\mathrm{fd}}$ for HCl-pretreated loess samples from CA and the CLP indicates that $\mathrm{HCl}$ dissolves the carbonates in the samples, and also reacts with the Fe ions of the magnetic minerals, decomposing the fine minerals in the SPS and causing the MS to decrease. The magnetic minerals in the loess from the Ili Basin, CA, mainly comprise coarse particles, and they have a relatively small contribution to the SP and the MS. $\chi_{\mathrm{lf}}$ and $\chi_{\mathrm{fd}}$ of AA-pretreatment CA samples were increased by $20.3 \%$ and $53.4 \%$, respectively, while those of CLP samples only increased by $4.8 \%$ and $13.2 \%$, respectively. AA affects MS to some extent, because carbonates have a much more significant influence on the MS of loess from CA than from the CLP. For most samples pretreated with $\mathrm{H}_{2} \mathrm{O}_{2}$ or distilled water, the variations in $\chi_{\text {lf }}$ were less than $5 \%$, which indicates that the soluble mineral contents and organic materials in the loess have a very small effect on the MS. Comparative analysis of TDS curves indicates that the transformation of magnetic minerals during the cooling of loess from the CLP mainly affected fine particles in the SP, and that the contents of lepidocrocite and maghemite or goethite in the Ili loess were lower than those in the CLP. The experiments indicate that the process of loess MS enhancement in Central Asia differs from that on the CLP, consistent with other geochemical and magnetism investigations. ${ }^{19-21,35,39,56,57}$ These results help in understanding the paleoclimatic significance and paleoenvironmental reconstruction in the Central Asia arid area.

\section{Conflicts of interest}

We have read your policy on conflict of interest and confirm that there are no conflicts to declare.

\section{Acknowledgements}

The project was supported by the Natural Science Foundation of China (No: 41572162), International Partnership Program (132B61KYS20160002) and Special Exchange Program for Russia, Ukraine, and Belarus from Chinese Academy of Sciences. We are grateful for critical comments and suggestions by Editor Dr Zhaohui Wang and two reviewers. We also thank Dr Dave Chandler for language editing and polishing.

\section{References}

1 Z. S. An, Quat. Sci. Rev., 2000, 19, 171-187.

2 Z. S. An, G. J. Kukla, S. C. Porter and J. L. Xiao, Quat. Res., 1991, 36, 29-36.

3 Z. S. An, J. E. Kutzbach, W. L. Prell and S. C. Porter, Nature, 2001, 411, 62-66.

4 Q. Hao, L. Wang, F. Oldfield, S. Peng, L. Qin, Y. Song, B. Xu, Y. Qiao, J. Bloemendal and Z. Guo, Nature, 2012, 490, 393396.

5 S. B. Marković, T. Stevens, G. J. Kukla, U. Hambach, K. E. Fitzsimmons, P. Gibbard, B. Buggle, M. Zech, Z. Guo, Q. Hao, H. Wu, K. O'Hara Dhand, I. J. Smalley, G. Újvári, P. Sümegi, A. Timar-Gabor, D. Veres, F. Sirocko, D. A. Vasiljević, Z. Jary, A. Svensson, V. Jović, F. Lehmkuhl, J. Kovács and Z. Svirčev, Earth-Sci. Rev., 2015, 148, 228-258.

6 I. Obreht, C. Zeeden, U. Hambach, D. Veres, S. B. Marković, J. Bösken, Z. Svirčev, N. Bačević, M. B. Gavrilov and F. Lehmkuhl, Sci. Rep., 2016, 6, 36334, DOI: 10.1038/srep36334.

7 G. Újvári, T. Stevens, M. Molnár, A. Demény, F. Lambert, G. Varga, A. J. T. Jull, B. Páll-Gergely, J.-P. Buylaert and J. Kovács, Proc. Natl. Acad. Sci. U. S. A., 2017, 114, E10632E10638.

8 B. Buggle, B. Glaser, U. Hambach, N. Gerasimenko and S. Marković, Quat. Int., 2011, 240, 12-21.

9 S. B. Marković, U. Hambach, T. Stevens, M. Jovanović, K. O'Hara-Dhand, B. Basarin, H. Lu, I. Smalley, B. Buggle, M. Zech, Z. Svirčev, P. Sümegi, N. Milojković and L. Zöller, Geol. Mijnbouw, 2012, 91, 173-188.

10 Q. S. Liu and C. L. Deng, Chin. J. Geophys., 2009, 52, 10411048.

11 J. Nie, J. W. King and X. Fang, Geophys. Res. Lett., 2007, 34, L19705, DOI: 19710.11029/12007GL031430.

12 Q. Hao and Z. Guo, J. Geophys. Res.: Solid Earth, 2005, 110, B12101, DOI: 12110.11029/12005JB003765. 
13 B. A. Maher and R. Thompson, Geology, 1991, 19, 3-6.

14 J. S. Nie, Y. G. Song, J. W. King and R. Egli, Quat. Sci. Rev., 2010, 25, 261-266.

15 L. P. Zhou, F. Oldfield, A. G. Wintle, S. G. Robinson and J. T. Wang, Nature, 1990, 346, 737-739.

16 G. Kukla and Z. S. An, Palaeogeogr., Palaeoclimatol., Palaeoecol., 1989, 72, 203-225.

17 F. Heller and T. S. Liu, Geophys. J. R. Astron. Soc., 1984, 77, 125-141.

18 X. M. Meng, E. Derbyshire and R. A. Kemp, Quat. Sci. Rev., 1997, 16, 833-839.

19 Y. Liu, Z. T. Shi, C. L. Deng, H. Su and W. X. Zhang, Geophys. J. Int., 2012, 190, 267-277.

20 Y. G. Song, Adv. Sci. Lett., 2012, 6, 167-172.

21 Y. G. Song, Z. T. Shi, H. M. Dong, J. S. Nie, L. B. Qian, $\mathrm{H}$. Chang and X. K. Qiang, Presented in part at the IEEE Intl Geosci Remote Sen Symp, Boston, MA, United States, 2008, vol. 2, pp. 1227-1230.

22 J. Zan, X. Fang, S. Yang and M. Yan, Geochem., Geophys., Geosyst., 2015, 16, 101-111.

23 G. Li, D. Xia, M. Jin, J. Jia, J. Liu, S. Zhao and Y. Wen, Quat. Int., 2015, 372, 87-96.

24 K. E. Fitzsimmons, T. Sprafke, C. Zielhofer, C. Günter, J.-M. Deom, R. Sala and R. Iovita, Quat. Int., 2016, 1-14, DOI: 10.1016/j.quaint.2016.1007.1041.

25 X. Liu, Quat. Int., 2012, 279-280, 283.

26 B. A. Maher, Quat. Sci. Rev., 2016, 154, 23-84.

27 B. Lü, X. Liu, Q. Chen, G. Y. Zhao, C. J. Sheng, X. G. Mao and X. L. Guo, Chin. J. Geophys., 2012, 55, 3077-3087.

28 J. Chen, H. T. Wang and H. Y. Lu, Acta Geol. Sin., 1996, 70, 61-72.

29 L. W. Liu, H. T. Wang, Y. Chen and J. Chen, Acta Petrol. Mineral., 2002, 21, 69-73.

30 J. M. Sun and T. S. Liu, Earth Planet. Sci. Lett., 2000, 180, 287296.

31 X. F. Hu, Acta Pedol. Sin., 2004, 41, 7-12.

32 R. F. Jia, T. S. Liu and B. H. Lin, Geochimica, 1992, 234-242.

33 Y. G. Song, X. L. Chen, L. B. Qian, C. X. Li, Y. Li, X. X. Li, H. Chang and Z. S. An, Quat. Int., 2014, 334, 61-73.

34 Y. G. Song, C. X. Li, J. D. Zhao, P. Cheng and M. X. Zeng, Quat. Geochronol., 2012, 10, 2-7.

35 Y. G. Song, Z. T. Shi, X. M. Fang, J. S. Nie, I. Naoto, X. K. Qiang and X. L. Wang, Sci. China: Earth Sci., 2010, 53, 419-431.

36 Y. Song, D. Luo, J. Du, S. Kang, P. Cheng, C. Fu and X. Guo, Geol. J., 2017, 1-10, DOI: 10.1002/gj.3129.
37 Y. G. Song, M. X. Zeng, X. L. Chen, Y. Li, H. Chang, Z. S. An and X. H. Guo, Asian J. Earth Sci., 2018, 155, 58-67.

38 S. G. Kang, X. L. Wang, Y. C. Lu, W. G. Liu, Y. G. Song and N. Wang, Quat. Geochronol., 2015, 30, 181-187.

39 W. X. Zhang, Z. T. Shi, G. J. Chen, Y. Liu, J. Niu, Q. Z. Ming and H. Su, Environ. Earth Sci., 2013, 70, 2191-2202.

40 Y. Li, Y. G. Song, Z. P. Lai, L. Han and Z. S. An, Sci. Rep., 2016, 6, 32365, DOI: 10.1038/srep32365.

41 M. E. Evans and F. Heller, Earth-Sci. Rev., 2001, 54, 129-144. 42 J. Nie, Y. Song and J. W. King, Front. Earth Sci., 2016, 4, 27, DOI: $10.3389 /$ feart.2016.00027.

43 J. Zan, X. Fang, M. Yan and B. Li, Geophys. J. Int., 2017, 208, 663-673.

44 S. Kang, Y. Lu and X. Wang, Quat. Geochronol., 2011, 6, 480490.

45 B. A. Maher and R. Thompson, Quat. Res., 1992, 37, 155-170. 46 Q. Liu, C. Deng, J. Torrent and R. Zhu, Quat. Sci. Rev., 2007, 26, 368-385.

47 Q. Liu, J. Torrent, B. A. Maher, Y. Yu, C. Deng, R. Zhu and X. Zhao, J. Geophys. Res.: Solid Earth, 2005, 110, B11102, DOI: $10.1029 / 2005 J B 003765$.

48 X. L. Guo, X. M. Liu, B. Lv, D. P. Tang, X. G. Mao, J. S. Chen and X. Y. Chen, Chin. J. Geophys., 2011, 54, 1854-1862.

$49 \mathrm{~W}$. Ye, The characteristics and paleclimate of loess deposits in Westerly area, Ocean Press, Beijing, 2001.

50 R. X. Zhu, M. Lin and Y. X. Pan, Chin. Sci. Bull., 1999, 44, 8186.

51 C. P. Hunt, S. K. Banerjee, J. Han, P. A. Solheid, E. Oches, W. Sun and T. Liu, Geophys. J. Int., 1995, 123, 232-244.

52 C. L. Deng, R. X. Zhu, M. J. Jackson, K. L. Verosub and M. J. Singer, Phys. Chem. Earth, 2001, 26, 873-878.

53 C. L. Deng, R. X. Zhu, K. L. Verosub, M. J. Singer and B. Yuan, Geophys. Res. Lett., 2000, 27, 3715-3718.

54 Q. S. Liu, C. L. Deng, Y. Yu, J. Torrent, M. J. Jackson, S. K. Banerjee and R. X. Zhu, Geophys. J. Int., 2005, 161, 102-112.

55 E. A. Oches and S. K. Banerjee, Stud. Geophys. Geod., 1996, 40, 287-300.

56 J. Jia, D. S. Xia, B. Wang, H. T. Wei and X. B. Liu, Quat. Int., 2012, 250, 84-92.

57 M. X. Zeng, Y. G. Song, Y. Li, C. F. Fu, X. K. Qiang, H. Chang, L. D. Zhu, Z. P. Zhang and L. Q. Cheng, Geol. J., 2018, 1-13, DOI: $10.1002 /$ gj.3182. 